\title{
Metodologija povijesti umjetnosti kroz prizmu stalnog postava Muzeja grada Šibenika
}

\section{Lambaša, Marina}

Source / Izvornik: Institucije povijesti umjetnosti : zbornik 4. kongresa hrvatskih povjesničara umjetnosti, 2019, 163 - 166

Conference paper / Rad u zborniku

Publication status / Verzija rada: Published version / Objavljena verzija rada (izdavačev PDF)

https://doi.org/10.31664/z4khpu.22

Permanent link / Trajna poveznica: https://urn.nsk.hr/urn:nbn:hr:254:992047

Rights / Prava: Attribution 4.0 International/Imenovanje 4.0 međunarodna

Download date / Datum preuzimanja: 2023-04-26

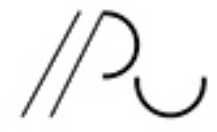

INSIITUTR ZA POVIJEST UMJETNOST
Repository / Repozitorij:

PODEST - Institute of Art History Repository

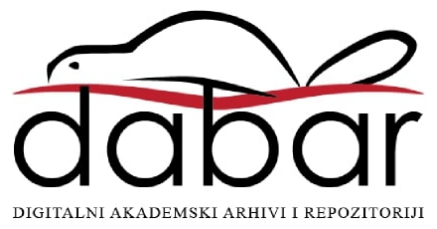




\section{Metodologija povijesti umjetnosti kroz prizmu stalnog postava Muzeja grada Šibenika}

Stalni postav Muzeja grada Šibenika otvoren u rujnu 20I2. godine u službi je prezentacije i komunikacije šibenske prošlosti od prapovijesti do danas (iako je realiziran dio do pada Mletačke Republike I797.) te prezentira cilj i osnovu muzejskog poslanja. ${ }^{1}$

$\mathrm{S}$ muzeološkoga gledišta stalni je postav poseban diskurs $\mathrm{u}$ kojem je (uz prezentaciju muzejskog fundusa i njegova bogatstva) žarište na priči, odnosno na posjetitelju, te se, kao uglavnom i na drugim općim izložbama, naglašava obrazovni, informativni karakter. Sa stanovišta dokumentacije i realizacije sama projekta problem je mnogo širi te ovdje valja naglasiti važnost postavljenih ciljeva u realizaciji te usuglašavanja temelja takve široke i duboke prezentacije, osobito unutar različitih disciplina, pa tako gledajući, i nove interpretacije, kao i različitosti koje svaki muzejski premet nosi. U tom smislu treba naglasiti posebnosti i razlike interpretacije i izložbene komunikacije među granama znanosti koje se $u$ muzeju susreću. Povijest umjetnosti kao znanost, u usporedbi s drugima, ističe važnost predmeta, originala, uz orijentaciju prema čistoj prezentaciji bez osobitih izložbenih i komunikacijskih pomagala. ${ }^{2}$

U stalnom postavu Muzeja grada Šibenika priču što vodi kroz kulturnopovijesni dio (ovdje izdvajamo arheološki dio stalnog postava koji funkcionira kao zasebna cjelina), odnosno dio od prvog spomena grada Šibenika u Krešimirovoj ispravi Io66. godine do pada Venecije, donose dvije, vrlo bliske i prepletene, metodologije, povijesna i povijesnoumjetnička, koje za posjetitelja, pa i stručnjaka, čine logičnu i nerazdvojnu cjelinu (sl. I). Gotovo je nemoguće u muzejskom predmetu izdvojiti svojstva koja se interpretiraju kroz povijesnoumjetničku metodologiju stila, interpretacije, analize, konteksta te onu povijesnu, koja ima svoje mjesto i u identifikaciji i interpretaciji svakog predmeta. ${ }^{3}$ Možda jedini nivo interpretacije prošlosti Šibenika i njezine prezentacije na kojem se povijest umjetnosti može

\section{Marina Lambaša}

Muzej grada Šibenika

marina.lambasa@muzej-sibenik.hr

https://orcid.org/oooo-ooo2-3396-557
I O muzejima i njihovu poslanju: ŽARKA vUJIĆ, Izvori muzeja u Hrvatskoj, Zagreb, Kontura art magazin, 2007.; o drugim pitanjima povijesti umjetnosti, likovnoj kritici i tumačenjima, te o suvremenim muzejima i njihovoj budućnosti: ŽELIMIR KOŠČEVIĆ, Kritike, predgovori, razgovori, I962.-20II., Zagreb, Durieux, 2012.

2 O konceptima interpretacije vidi u: PETAR PRELOG, Hrvatska umjetnost u kontekstu koncepata interpretacije srednjoeuropske umjetnosti od kraja I9. stoljeća do Drugog svjetskog rata, u: Zbornik II. kongresa hrvatskih povjesničara umjetnosti, (ur.) Irena Kraševac, Zagreb, 2007., 389-393.

3 TONKO MAROEVIĆ, Između dužnosti i malodušnosti, u: Zbornik II. kongresa hrvatskih povjesničara umjetnosti, (ur.) Irena Kraševac, Zagreb, 2007., 9-ıo: „Naši zaslužni prethodnici učinili su najviše što su mogli na otkrivanju i interpretaciji, na čuvanju i restauraciji domaćega umjetničkog nasljeđa. Ne samo što su spasili mnoge pojedinačne spomenike nego su i osvijestili cjelinu, približili nas sintezi i organskom poimanju povijesnih tokova. Uz razumijevanje regionalnog i nacionalnog konteksta pružili su nam univerzalne stilske i morfološke koordinate [...]". 


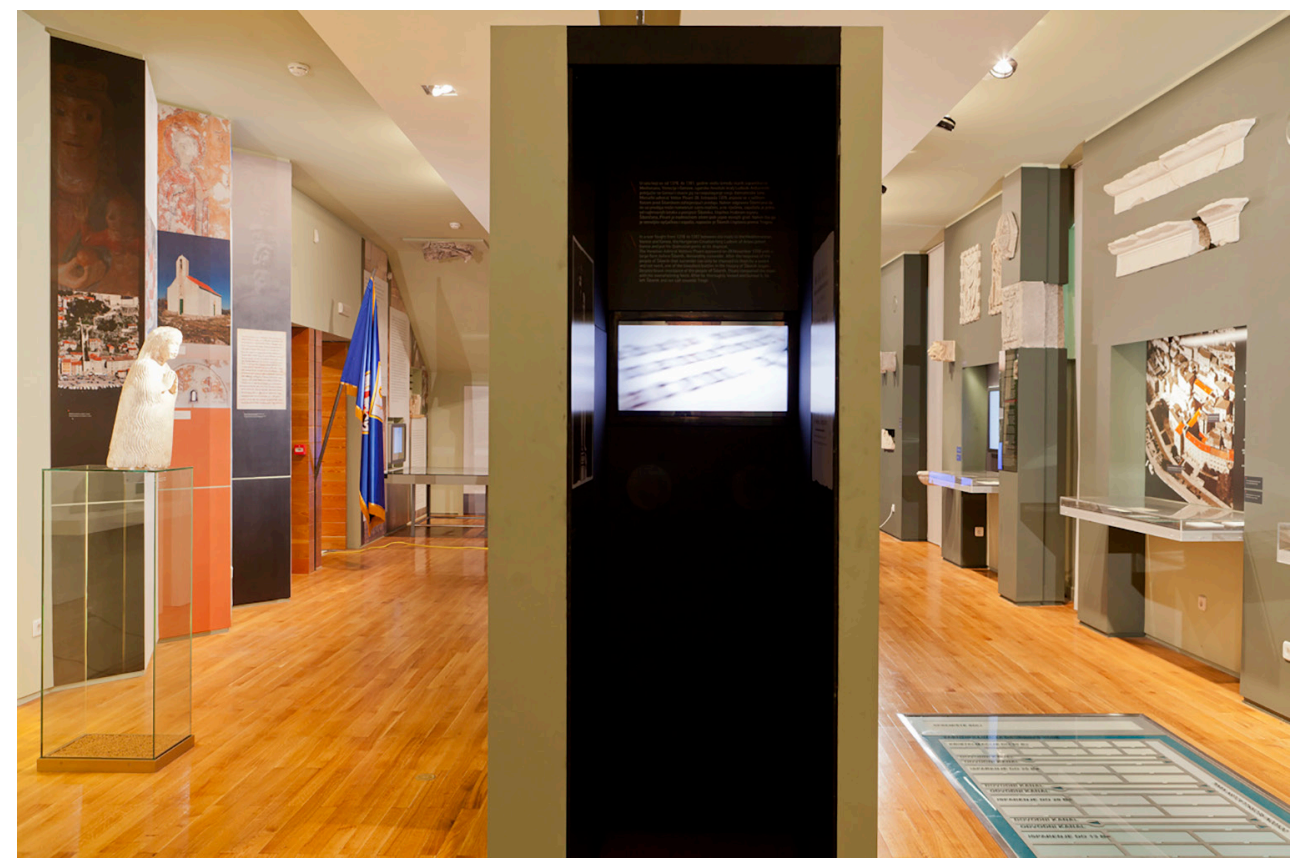

Slika I

Lijevo tema Šibenik u doba 12./13. stoljeća, desno tema Šibenik pod Venecijom (1412.1797.) s filmom o razaranju grada 1378. godine u sredini foto: T. Šmider identificirati i jasno izdvojiti jest onaj tematski, koji stavlja grupu predmeta u njihov zasebni okvir te funkcionira u korelaciji s ostatkom postava. Riječ je, dakle, o nekoliko tema koje se izdvajaju, kako iz osnovnoga kronološkog slijeda, tako i onog interpretacijskog. ${ }^{4}$

Tematski okvir postavljen je tako da se kroz primjere tema koje se prepleću u stalnom postavu kao jedinstvenom diskursu prezentacije otvori rasprava o metodologiji i pristupu povijesti umjetnosti kao discipline muzejskom predmetu i njegovu kontekstu te da se uoče posebnosti i razlike u povijesnoumjetničkoj analizi i interpretaciji predmeta u odnosu na fokuse drugih znanosti. ${ }^{5}$ Gotička umjetnost I4. stoljeća kao tema koja se pojavljuje uz povijesni okvir osnivanja Šbenske biskupije I298. godine i početka mletačke uprave u Šibeniku I4I2. godine kao dvije referentne točke prepleće se sa cijelim kulturnopovijesnim kontekstom, odnosno pisanom riječi, umjetničkim obrtom i arhitekturom.

Veliku temu koja zaokuplja središnji dio prostornog, ali i konceptualnog razdoblja unutar mletačke uprave teško je nasloviti, recimo Šibenik u I5. i na početku i6. stoljeća, vrijeme gradnje katedrale, odnosno Šibenik kao umjetnički centar Dalmacije, odnosno ekonomski, politički, humanistički temelj umjetničkom zaletu... Unutar tako postavljena konteksta stvara se posljedično logična cjelina povijesnoumjetničkog fenomena katedrale svetog Jakova, i svakako jedinstvene umjetničke ličnosti Jurja Dalmatinca. Taj veliki centralni tematski blok generira teme gotičko-renesansnog slikarstva i kiparstva te umjetničkog obrta (sl. 2). Umjetničko djelo takvom prezentacijom, odnosno promatranjem unutar različitih kontekstnih krugova, dobiva smisao i interpretaciju koju je teško ostvariti
4 O mogućnostima tumačenja i izložbenoj komunikaciji umjetničkog djela u: NIKOLA ALBANEŽE, Interpretacija i izložbena komunikacija, u: Zbornik II. kongresa hrvatskih povjesničara umjetnosti, (ur.) Irena Kraševac, Zagreb, 2007., 233: „Postoje zapravo, pojednostavljeno govoreći, dvije mogućnosti. Prva mogućnost jest tumačenje $u$ povijesnom kontekstu, dakle kada artefakt percipiramo kao simptom određenog vremena i prostora, što nužno podrazumijeva usporedbu s drugim proizvodima njegova vremena ili prethodnih razdoblja. To je pozitivistički pristup koji nas vodi do faktografske razine, odnosno egzemplarno-povijesni kojim utvrđujemo, primjerice, stilove itd. Postoji i druga mogućnost, a to je tumačenje $u$ hermetičnom smislu, kako to likovna kritika, pogotovo nekritična, ona koja 'povijesno-umjetničku perspektivu' ne uzima toliko u obzir, često čini i tada djelo dolazi u apsolutno, izolirano središte. Posljedica je, kako sam već rekao, autonomija umjetničkog djela."

5 TONKO MAROEVIĆ (bilj. 3), Io: „Imamo pravo na izbor i preferencije (dapače, obavezni smo birati, čak eliotovski konstituirati vlastitu genealogiju uzora ili modela), no dužni smo pritom ponuditi odgovarajuću argumentaciju i dokumentaciju, konfrontirati vlastite razloge $\mathrm{s}$ motivacijom ostalih sudionika $\mathrm{u}$ valorizaciji." 
u drugom diskursu, a time taj muzejski predmet uz povijesnoumjetničku interpretaciju dobiva i društvenu ulogu koju je i u trenutku nastajanja imao (sl. 3). ${ }^{6}$ Za razliku od te velike cjeline koja je pokretač različitih drugih podtema, kroz I7. i I8. stoljeće pojavljuju se manje cjeline iznikle iz jakoga povijesnog okvira (sl. 4). Riječ je o povijesnoumjetničkim temama poput baroknih oltara, kasetiranih stropova, povijesnim orguljama u Šibeniku, dok se kao središnja tema kulture baroknog vremena u Šibeniku nameće humanistički krug i snažna grafička
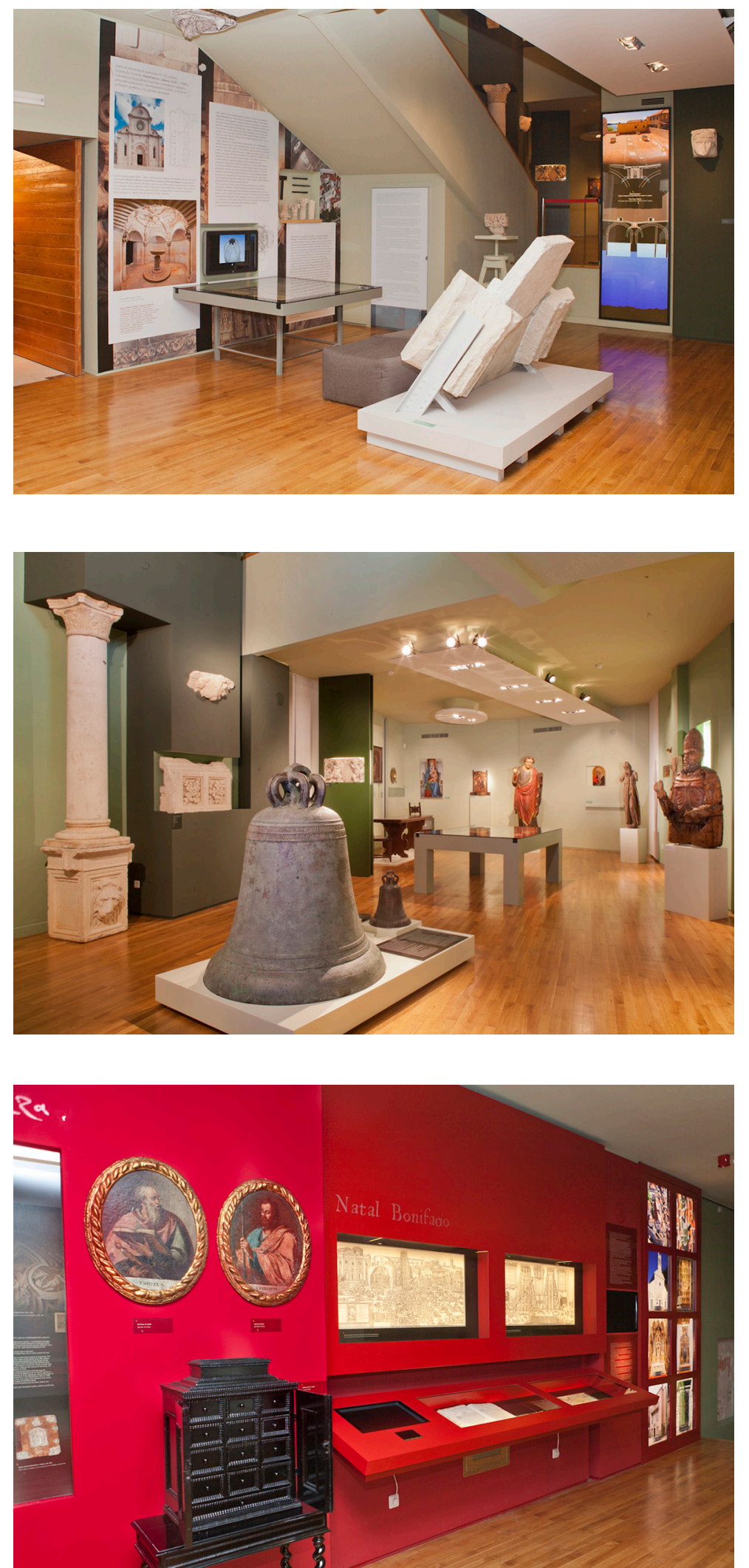

6 TONKO MAROEVIĆ (bilj. 3), ıo: „Naime, odnos prema prošlosti nužno nosi obilježja sadašnjosti, školovani smo da spomenike gledamo iz perspektive suvremenosti, to više što starenje umjetnine ne znači neizbježno i zastarijevanje njezine bitne emanacije, nego ponajprije mijenjanje značenja i pomicanje naglaska s jednog aspekta na drugi. Utoliko je interpretacija uvjetovana poštivanjem nataloženih slojeva, no slobodna u mogućnostima prevrednovanja ustaljenih hijerarhijskih odnosa."

Slika 2 Arhitektonsko-

kiparski studio Katedrale suetog Jakova

foto: T. Šmider

Slika 3

Umjetnost gotike i renesanse s izdvojenim temama Šibenska zuona i Renesansna loža

(vijećnica)

foto: T. Šmider

Slika 4

Teme Barokni Šibenik i

Znameniti Šibenčani, s

izdvojenim humanističkim

krugom

foto: T. Šmider 
djelatnost s iznimnim predstavnicima: Fortezza, Bonifačić, Martin Kolunić Rota. Važno je usto napomenuti da povijesnoumjetničke teme koaliraju s povijesnim, kao što je kontekst ekonomskih prilika, ratova i osmanskih osvajanja, kuge, ili političkih preferencija Mletačke Republike. Važno je da se i u prezentaciji, pa i analizi i interpretaciji umjetnosti, uključuju političko-ekonomske situacije, što se očituje kroz jaki hrvatski karakter grada, uporabu hrvatskog jezika, jaku crkvenu umjetnost. U kompleksnom izlaganju, koje se koristi svim mogućnostima interpretacije, ipak se mnogo toga mora ostaviti gledatelju, pa se ponekad važnost sama umjetničkog djela naglašava njegovom indirektnom ne-interpretacijom, odnosno osnovnim komunikacijskim načelima-jasnom i nedvosmislenom informiranju.

Povijest umjetnosti kao disciplina koja funkcionira u korelaciji $\mathrm{s}$ drugim, osobito bliskim disciplinama, povezuje se $u$ jedinstvenoj priči koja se može nazvati sveukupni pogled na prošlost kroz materijalne i nematerijalne izvore. Kroz analizu i interpretaciju na brojnim razinama oni prelaze iz pojedinačnih točaka u rasporedu unutar jedne od disciplina (diskursa) u niz, odnosno drugi kontekst, koji tvori znanstveno dokazan povijesni tijek te ulazi u sve discipline, odnosno u njihove već zadane parametre. ${ }^{7}$ Predmet, u ovom slučaju umjetničko djelo, ulaskom u muzejski fundus postaje muzejski predmet te se na taj način obrađuje i analizira, a interpretira se i valorizira kroz spektar povijesnoumjetničkih metoda. Na taj način muzejski predmet/umjetničko djelo dobiva drukčiji kontekst, za razliku od predmeta koji se povijesno, arheološki ili drukčije interpretiraju, što rezultira i drukčijim zahtjevima za prezentaciju. Naime, kod predmeta/tema koje se interpretiraju (prezentiraju i gledaju) metodologijom povijesti umjetnosti, sadržaj komunikacije u prezentaciji u osnovi je umjetnički (sadržava podatke o autoru/umjetniku, stilu, autentičnosti, ikonografiji, i dr.).

Primjer stalnog postava Muzeja grada Šibenika omogućuje nam prikaz ograničenja i mogućnosti povijesnoumjetničke metodologije s primjenom na predmet kao osnovnu jedinicu. Stupnjevi interpretacije prate osnovni povijesni (politički i ekonomski) kostur, što se pomalo mijenja uvođenjem scenarija na osnovi tema, koji u nekim dijelovima u potpunosti dopušta primjenu metodologije povijesti umjetnosti. Stoga primjena prakse suvremene muzeologije i povijesnoumjetničke metodologije, u interpretacijskim, komunikacijskim i drugim procesima u muzejima, kao što je tematsko oblikovanje stalnog postava, dovodi do jasnijeg i kompletnijeg viđenja umjetničkog djela.

\section{(ㄷ) (1)}

Metodologija povijesti umjetnosti kroz prizmu stalnog postava Muzeja grada Šibenika/ Marina Lambaša / CC BY / 4.0

DOI: https://doi.org/Io.3I664/z4khpu.22
O problemima interdisciplinarnosti tema, osobito unutar muzeja, vidi u: STANKO ANDRIĆ, Arheolozi, povjesničari umjetnosti i povjesničari u istraživanju slavonskog srednjovjekovlja: prilog za bilancu uzajamnih dugovanja, u: Zbornik II. kongresa hrvatskih povjesničara umjetnosti, (ur.) Irena Kraševac, Zagreb, 2007., 4I7-4I8. 